\title{
Matate, Débil, Precoz: derivas del lenguaje en la trilogía de Ariana Harwicz
}

\author{
Matate, Débil, Precoz: Language drifts \\ in Ariana Harwicz's trilogy
}

\section{Gabriela Ponce Padilla}

Universidad San Francisco de Quito

DOI: https://doi.org/10.32719/13900102.2018.44.3

Fecha de recepción: 25 enero 2018

Fecha de aceptación: 27 marzo 2018 


\section{RESUMEN}

La trilogía de Ariana Harwicz, que reúne las novelas Matate, amor, La débil mental y Precoz, es analizada en este artículo a partir de los modos en los que el lenguaje traduce y materializa la experiencia del cuerpo femenino, atravesado por la violenta y paradojal presencia de lo materno.

Palabras clave: Ariana Harwicz, Argentina, novela, maternidad y abyección, fenomenología y lenguaje, palabra y performatividad.

\section{ABSTRACT}

The trilogy by Argentinian writer Ariana Harwicz, which brings together the novels Matate, amor, La débil mental y Precoz, is analyzed in this article with basis on the ways in which language translates and materializes the experience of the female body as traversed by the violent and paradoxical presence of the maternal.

KeYwords: Argentina, Ariana Harwicz, novel, maternity and abjection, phenomenology and language, word and performativity.

Incomensurable, ilocalizable cuerpo materno Julia Kristeva, "Stabat Mater", Historias de amor

Ariana Harwicz (Buenos Aires, 1977) escribe tres novelas que funcionan como una trilogía. Matate, amor (2012), La débil mental (2014) y Precoz (2015), comparten una temática en la que obsesivamente asoma el tema de la maternidad. La presencia, en las tres novelas, del cuerpo de la madre (o de la hija) en estado de vertiginosa pérdida, se puede leer desde la imagen que plantea Julia Kristeva al referirse a lo abyecto como eso que "solicita y pulveriza simultáneamente al sujeto" (Kristeva 2013, 12). Lo novedoso de esta aproximación hacia lo maternal radica en que dicha imagen se vuelca en esta trilogía hacia el lenguaje, a través de un procedimiento simultáneo que lo intensifica llevándolo hasta sus límites: cierta concentración expresiva - diríamos poética- en la que la frase se carga de significados e imágenes en potencia, desatando una violencia rítmica que se desborda a sí misma. Dotándole, por otro lado, a la temporalidad de la escritura de un presente en el que se distingue eso que Merleau-Ponty (1993, 191-216) llama el carácter existencial de la palabra, y que expresa su condición fenoménica, encarnada e incompleta.

La trilogía, publicada en el lapso de tres años, ocurre en paisajes en donde la voz femenina vaga en una suerte de nomadismo interior que 
se espejea con territorios agrestes que mientras la amparan, también la expulsan. En Matate, amor, esa voz concentra la desolación de una madre que enfrenta los primeros meses de vida de su hijo asechada por deseos paradójicos. La novela transcurre en medio de un paraje silvestre en el que lo doméstico acorrala a la madre de modos siniestros y delirantes hasta el límite de la cordura. La débil mental es el apasionado retrato de la relación entre una hija y su madre nuevamente desde la perturbación de un vínculo "tan tranquilizador como asfixiante" (Kristeva 2013, 22), que anuncia a lo largo de la novela una catástrofe en la que lo único que pervive es la perversidad de ese mandato femenino del que no se escapa. Finalmente, Precoz muestra el recorrido por un lapso de tiempo en la vida de una madre y su hijo adolescente. Otra vez asistimos a un paisaje que sugiere marginalidad, atmósfera que va saturándose de una sensualidad que solicita el cuerpo de la madre hasta su desplome. Las tres novelas muestran un mundo interior en cuyo extravío se pone de manifiesto la tensión entre esa intemperie y el éxtasis del cuerpo que la habita.

\section{IMAGEN E IMPOSIBILIDAD: EL EXCESO COMO RITMO EN LA TRILOGÍA}

El cuerpo femenino en esta trilogía -en su condición tanto de madre como de hija- organiza su experiencia perceptual ${ }^{1}$ a partir del deseo y su errar. Lo abyecto, como manifestación precisamente de ese fallo, que resulta ser un fallo de origen (Kristeva), confronta a un sujeto a quien le "ha sido develado que todos sus objetos solo se basan sobre la pérdida inaugural fundante de su propio ser" (Kristeva 2013, 12). La maternidad opera como abyección en tanto repuja ese carácter de oquedad del cuerpo, rememorando la falta fundante que a su vez es impulso apasionado hacia el objeto (hijo). El hueco que ha dejado la criatura parece radicalizar la crisis que llega, en el caso de Harwicz, a instalarse en la escritura, en un doble movimiento que satura al tiempo que vacía.

1. Merleau-Ponty (1993) sostiene que es el cuerpo el que nos abre al mundo y nos pone en situación, es a través de un cierto "esquema corpóreo" que se reanuda a cada instante y a través del cual organizamos la experiencia perceptual (181-90). 
En las páginas de esta trilogía, el deseo al devenir siempre insatisfacción se redirecciona en un arrojo que no cesa. En el flujo escritural de Harwicz se despliegan cadenas de enunciados concentrados, frases breves se suceden unas a otras, en una corriente que se desborda continuamente a sí misma, reorientándose para implicarse en una nueva estructura de deseo. La operación que parece suceder en su interior se asemeja a la contención que carga la flecha antes de disparase y que cuaja en un disparo certero y fulminante, para cargarse de manera inmediata nuevamente de tensión. $\mathrm{O}$ a la contracción en cuyo ritmo incremental el feto se conduce hacia su expulsión también desbordando los órganos. Esto se expresa en las tres novelas como monólogo del exceso. Así lo podemos percibir en esta cita, en cuya extensión se ilustra ese carácter:

Mamá, yo, corro y me arrojo desde un pozo de lluvia a los altos pastizales no podados. Donde mi cuerpo quedará años sin ser descubierto y será verdad forense. Mi aliento de búfalo me sofoca. Podría empañar vidrios enteros, los ventanales de un castillo, ciudades espejadas por ríos angostos. Soy una bestia que respira lento y pesado, que saca el aire al resto. Miro la noche y me parece un baúl con candado. Un viejo vagón que va al infierno. Busco en el aire tupido la grieta por donde atenuarme. ¿Qué querés de mí?, dice mi marido. ¿Qué necesitás ahora? ¿Hay algo que pueda hacer? $Y$ me pone delante un almohadón. Pero un almohadón no me alcanza. Pego una piña al aire y mi esposo sale corriendo y regresa con un par de guantes de boxeo rojo de su adolescencia. Me los pone, pego tontamente dos porrazos cruzados a su nariz y me los saco. No quiero guantes de ring. No quiero paragolpes. Quiero ver mis manos hechas de hueso dispararse en todas las direcciones. Cogeme le grito con una voz que me sonó perruna. Cogeme de una buena vez. Pero lo que tenía ganas de hacer mientras se acercaba a mí erecto era comer flores venenosas, champiñones venenosos, piedras. Acabar ese largo día difuso, tormentoso. Me tiró sobre la cama, el bebé seguía frente a las maderas cortadas, se estiraba para tomar la sierra. Me abrió las piernas. Me hurgó con sus manos callosas. Cuando grito cogeme lo que menos hay es apetito. Y mientras entraba su pedazo de carne saliente en mi hueco, si eso es hacer el amor, estamos locos, deseé una habitación blanca por la que entre el aire de mar, la sal picante en mi lengua cortejada. Alguien me cura los ojos, adiestra mi mirada y me deja en un lugar infinitamente más calmo que este chiquero. Ese otro escarba en mí buscando oro. Porque hay otro. Pero nadie sabe escarbar. Ni siquiera él. Cuando mi marido se achicó y salió sentí que palpitaba y, aunque lo mordí, lo amé. La sierra empezó a andar (Harwicz 2012, 61-62). 
La imaginería poética de Harwicz revienta la frase descolocando el significado, poblándolo de imágenes potenciales, en una apertura que funciona de manera paradójica: la frase corta, y mientras tensiona la lengua la abre en su capacidad de significar. En esa contradicción, de resistir y liberar, aparece la potencia poética que funciona desde la desactivación de la palabra. Giorgio Agamben, en su ensayo “¿Qué es la creación?”, plantea una problemática que parece existir en el seno de la potencia, en la que la resistencia que impone la-potencia-de-no (constituyente de toda potencia) singulariza la creación: aparece la voz del creador. La voluntad de quien en el acto de creación suspende para contemplar, manifestándose lo que “se resiste y se opone a la expresión” (Agamben 2016, 49). Esto sucede a través de una acción que desactiva y vuelve inoperosa la obra, a la vez que la abre a nuevos usos posibles. En la trilogía, es en ese juego de desactivaciones que habitan en el interior del lenguaje en donde aparece el estilo, tan particular, tan feroz y poderoso de la prosa poética de Harwicz. En lo que parece ser una constante apertura de la palabra se percibe, invisible por debajo del texto, una suerte de resistencia que expande su polisemia y lleva la frase hasta sus límites:

[...] cuando tengo sexo conmemoro aniversarios de ausencia. Cuando me enamoro, ahora mismo, mientras me sacudo, echo tierra sobre un cajón. Qué importa de quién. Y cuando me masturbo profano nichos y cuando acuno a mi bebé digo amén y cuando sonrío desconecto un respirador artificial. Por eso el beso, porque, de todos modos, desde hace tanto, incluso, desde antes de nacer y mientras mi esposo anda gritado por ahí de celos, estoy muerta (Harwicz 2012, 57).

Esa misma condensación poética desata en los textos un ritmo que se dispara de manera visceral en la escritura. El ritmo pone en relación al estructurar pulsos, ciclos, reiteraciones (Agaud 2015, 27-29); es decir, ordena la experiencia temporal que se dispone de manera iterada para resonar. La existencia rítmica de una obra presupone, entonces, la estructuración de un proceso que también mientras vincula va particularizando. Ese impulso de composición que encarna esa doble condición, y que pone en diálogo la singularidad orgánica y sensible de un ser -el pulso, el latido, el flujo sanguíneo- con un entorno o con un material, se resuelve a través de una combinatoria que despliega y con-forma el movimiento de esa obra, enlazando la experiencia estética con la vital (López 2015, 177-78). 
En el caso de Harwicz, la rítmica en su trilogía propone una combinación de repetición y contraste que pone de manifiesto la paradojal situación del cuerpo maternando: el desplazamiento desde sus impulsos más primitivos hacia las constricciones de la condición cultural/política impuestos a ese cuerpo. La condición que solicita desde el cuerpo, y que a la vez la experiencia de lo cultural niega (Kristeva), se expresa en la violencia de las frases que se imprime en el ritmo:

Cuando mi marido se va de viaje, a cada segundo de silencio le sigue una horda de demonios colándose por mi cerebro. Una rata salta sobre el techo transparente. Parece divertirse la loca. Voy a ver si el bebé respira a cada minuto, lo toco para ver si reacciona, lo destapo, lo cambio de posición, lo ilumino, lo levanto, todavía estamos en la etapa de la muerte blanca. Después me controlo, me hago un sándwich y me quedo frente a la tele. Pero enseguida el ajjj, ajjj de un búho, ese sonido genital, involuntario y erótico me aterra. Apago la tele. Imagino a los animales en una orgía, un ciervo, una rata y un jabalí. Me río, pero inmediatamente me da miedo esa mezcolanza de bicharracos. Esas patas, colas y pelambres enganchados en una carrera de placer. ¿Cómo eyaculará un jabalí? [...] Entre las dos y las cuatro de la mañana viene lo peor, después afloja y vuelvo a hacerme de comer [...] Me veo yendo al bosque y dejando el cochecito cuesta abajo. Ajjj, ajjj, por suerte suena el teléfono [...] A veces quiero que llore para poder colarme en su cama sin culpa y descargar mis tetas (Harwicz 2012, 16-17).

En su aproximación a lo abyecto, Kristeva se refiere a quien se le manifiesta la abyección como el "arrojado" que:

[...] en lugar de preguntase por su ser, se interroga sobre su lugar. Ya que el espacio que preocupa al arrojado, al excluido, jamás es uno, ni homogéneo, ni totalizable, sino esencialmente divisible, plegable, catastrófico. Constructor de territorios, de lenguas, de obras, el arrojado no cesa de delimitar su universo, cuyos confines fluidos -estando constituidos por un no objeto, lo abyecto- cuestionan constantemente su solidez y lo inducen a empezar de nuevo [...] (Kristeva 2013, 16).

A la luz de esta reflexión y de la cita que la precede, en los personajes femeninos de Harwicz -específicamente en Matate, amor-, podemos observar cómo la maternidad produce un extravío que arroja a la madre hacia los límites que la separan del paisaje y del animal. El contorno que distingue a su cuerpo de esos cuerpos que asechan desde el campo se 
vuelve movimiento que extravía la identidad, mostrando su imposibilidad, haciéndola empezar cada vez de nuevo: "Creo que no pensé en nada en toda mi vida. Pateo piedras al lado del camino. Ahora soy una turba de aves nocturnas. Ahora soy una imposible horrible maravillosa noche. Ahora una avalancha hueca" (Harwicz 2012, 25).

El cuerpo que se vacía además a través de sus flujos, al ritmo de la leche y de la sangre -en el caso de Harwicz- desborda la voz poética, como dice Hélene Cixoux: "Voz: la leche inagotable. Ha sido recobrada la madre perdida. La eternidad: la voz mezclada con la leche" $(1995,56)$. Ese fluir aparece en Matate, amor consumiendo la palabra e inventando una lengua $-\mathrm{y}$ un ritmo- radicalmente corporal:

Escuché un disparo y di vuelta la cabeza con la misma intriga cándida de los bambis. Paré las orejas. ¿Qué fue ese estruendo? ¿Dónde está el bebé? Mi corazón se aceleró tanto que pensé que lo vería embarrado en las hojas caídas. Después lo busqué como solo una madre busca a su hijo. No corriendo ni caminando, no mediante acciones físicas. Lo encontré acostado sobre unas ramas más altas que lo que yo hubiese trepado. Me hacía cu-cu ma-ma con la mano. Apenas camina y ya pudo treparse a un árbol. He parido a un pequeño bárbaro. Subí y nos quedamos abrazados [...] Unas voces dicen nuestros nombres que ya olvidamos. Nos buscan. Bla bla bla o co co ri co da igual. Mejor harían en cerrar el pico. Los animales se burlan de ellos. El ciervo se detiene como embalsamado, los ojos de vidrio. Está conmovedoramente quieto. Él es mi hombre. El que sabe mirar mi tristeza infinita. Los otros son apenas hombres. De qué sirve ser uno de ellos si el idioma no alcanza (Harwicz 2012, 69-70).

El ritmo del cuerpo es flujo que sin embargo está quebrándose de manera recurrente, golpeando cualquier posible unidad. Dice Merleau-Ponty que el esquema a través del cual se reanuda -a cada instante- la implicación del ser con su entorno ocurre en y a través del cuerpo, es siempre experiencia encarnada. En la segunda parte de su texto Fenomenología de la percepción, titulada "El sentir", en la que se explora las dimensiones entrelazadas entre el sujeto de la sensación y lo sensible, Merleau-Ponty se refiere específicamente al "ritmo existencial" que se reanuda intencionalmente entre sujeto y objeto:

La sensación es, sin duda alguna, intencional, o sea, no se apoya en sí como una cosa, que apunta y significa más allá de sí misma. Pero el término al que apunta solo ciegamente es reconocido por la familiaridad que 
con él tiene mi cuerpo, no está constituido en plena claridad, lo restituye o lo reanuda un saber que permanece latente y que le presta su opacidad y su ecceidad. La sensación es intencional porque encuentro en lo sensible la proposición de cierto ritmo de existencia y que, llevando a efecto esta proposición, deslizándome en la forma de existencia que así se me sugiere, me remito a un ser exterior, tanto si es para abrirme como para cerrarme a él. Si las cualidades irradian a su alrededor cierto modo de existencia, si tienen cierto poder de hechizo [...] es porque el sujeto sensible no las posee como objetos sino que simpatiza con ellas, las hace suyas y encuentra en ellas su ley momentánea [...] $(1993,229)$.

Desde esta perspectiva, el ritmo está planteado en términos de una condición existencial del sujeto que modula dos experiencias -la suya y la del objeto- para la generación de un movimiento que los sincroniza y los arroja de manera mutua e intencional, el uno al otro. La apertura, el movimiento que crepita en el cuerpo, es el ritmo que como corriente se activa siempre en relación a una alteridad que lo seduce. En las voces femeninas de las tres novelas, el esquema parece sufrir una dislocación permanente que encuentra instantes intensificados de modulación precisamente sensual, con otro cuerpo al que se vincula, sin embargo, de modo siempre precario. De esta manera, la modulación -esta ley momentánea- opera en la rítmica de la prosa de Harwicz como un quiebre y una reconstitución que pone de manifiesto la condición de su inestabilidad. En su segunda novela, La débil mental, en la voz de la hija se distingue una economía narrativa en la que el vínculo erotizado, madre-hija, es modulado a partir de un movimiento de apertura/cierre que pone a vibrar la frase y marca el ritmo del texto:

Me despierta el clic clic de una $\mathrm{C} 11$ táctical equipada con rayo láser. $\mathrm{O}$ un olor a turba en el aire. O bardas de piedra y musgo. Me despierta un amor agridulce que no existe. No un amor, dedos larguísimos y salados. Restos de mierda de vaca en el aire. Me despierta la impresión de que todo el resto que no sea él eyaculando en mi culo, me estorba. Mamá arriba de mí excitada y yo que la soñé aplastada por un choche con cambios automáticos. La conductora de lentes gruesos gritando entre sus órganos, qué horror, pero varias veces. Huele a gas. Lo echaron sobre el nido de abejorros, ahora las gallinas dan vueltas frenéticas. Me desmayo, mamá (Harwicz 2014, 25).

En el caso de estas novelas, el cuerpo, instrumento general de comprensión que interroga cada vez la realidad (Merleau-Ponty 1993, 181- 
90), se hace palabra que irradia su significación en el significante, como escritura apasionada, encarnada, modulada en la experiencia breve y frágil del mundo. Es también, en ese sentido, que la palabra o la mirada se desplazan a través de una materialidad erotizada que obtiene de las cosas interrogando en ellas, deslizándose por su corporalidad: "La copa de la arboleda se mueve y es esa duna de caracolas marinas con una lona rasposa compartida por la abuela, mami y la niña. Un trío de trastes colorados sobre las almejas. Tres espaldas rollizas con crema protectora. Tres vaginas arenosas al final del día. Por fin doy con una taberna. Puede que el jamón o las langostas expuestas en la vitrina no estén en buen estado, pero igual pido eso, me siento en una mesa oscura, el cenicero rebalsa" (Harwicz $2014,71)$.

\section{PRESENTE DE LA ESCRITURA, PALABRA QUE PERFORMA}

Esa rítmica -ritmo de la carne-, que modula instantes a partir de los cuales ocurre una reanudación, deriva -en el caso de estas novelas- en una temporalidad también estriada. Volviendo a Kristeva, en su texto sobre lo abyecto, se señala que la fulminación le ocurre al sujeto al mismo tiempo que la solicitación se le manifiesta temporalmente:

el tiempo olvidado surge bruscamente y condensa en un relámpago fulgurante una operación que, si fuera pensada, sería la reunión de dos términos opuestos, pero que en virtud de dicha fulguración se descarga como un trueno. El tiempo de la abyección es doble: tiempo del olvido y del trueno, infinito velado y del momento en que estalla la revelación (Kristeva 2013, 17).

Este movimiento, que es a la vez instante y eternidad, produce un tiempo paradójico que en el caso de la escritura de Harwicz se plantea como suspensión que no deja de movilizarse, que no cesa pero tampoco se dirige hacia ninguna parte. Cada una de las novelas tiene un desarrollo: los personajes atraviesan un trayecto que, sin embargo, parece dejarlos en el mismo lugar y que, a través de imágenes que tensan el lenguaje, lo dinamizan vivamente. Las novelas se tejen a partir de instantes -acontecimientos inauditos- (Ricoeur 2008, 475), cuya fulguración desata vibraciones exaltadas al interior del personaje, que sueltan la palabra y estiran el tiempo. 
En este sentido, la condición de maternar se expresa como estasis. El tiempo de la madre se reviste de una eternidad que parece devorarla en su hueco profundo, fijando, en el caso de estas novelas, cualquier avance de la trama pero desatando -otra vez la paradoja- momentos poéticos que (des)componen la duración de las narraciones. La historia en Matate, amor empieza con una escena en la que la madre celebra los seis meses de su hijo y termina cuando el pequeño tiene dos años. En ese transcurso, la temporalidad se manifiesta a través de lapsos en los que la vida de la madre se intensifica por las crisis que atacan su cuerpo y que le dotan de vertiginosidad al tiempo de la novela. A lo largo de la narración la mujer atraviesa por algunos acontecimientos: la navidad y la muerte de su suegro, un plan de suicido, una relación con su vecino, un intento fallido por asesinar al padre de su hijo en el que termina matando a un perro, el matrimonio con el padre de su hijo, una crisis nerviosa que la lleva a ser hospitalizada, su accidentada recuperación y finalmente la celebración de los dos años del bebé, episodio que termina con el abandono de todo, ella se va. Este ordenamiento aparentemente cronológico de acontecimientos no se suceden sin embargo a partir de un transcurso lineal, sino como momentos que engendran quiebres temporales profundos. Son los escapes, los trances del cuerpo, sus pulsiones, los que marcan un devenir en el que el personaje regresa siempre a su mismo errar interior que es destiempo:

mi pichoncito tiene dos años y en mi mente sigo pujando, que ahí viene, que ya está, que ya se le ve la cabecita. Para soplar, mi esposo se puso detrás de mí y varias cámaras, apunten. Allí estuvimos para la eternidad de la foto, estampados, amurallados [...] y no sé por qué fijé la mirada en un montículo de tierra como uno podría mirar las estrellas, las galaxias, los satélites, imágenes de lo que pasó hace millones de años, el pasado mirando desde el presente (Harwicz 2012, 145-46).

La temporalidad de esta escritura que se manifiesta como presente nos remite a la definición que Merleau-Ponty plantea de la percepción en su carácter de reanudación - "reconstitución del mundo en cada momento-" $(1993,223)$, y que se refiere también a una naturaleza temporal en la que surge cada vez el sentido de la experiencia. La temporalidad existe como vivencia encarnada en cuyo despliegue suceden simultáneamente la rememoración que activa el pasado, y la prospección del futuro que se proyecta en un flujo de "ahoras" (Merleau-Ponty 1993, 420), en el 
que ocurre la subjetivación. El ser es tiempo en tanto siempre implica su existencia en una corriente que lo precede, y en la cual el presente es un movimiento simultáneo en el que ser y ser consciente son una misma cosa: "Hay tiempo para mí porque tengo un presente. Es al llegar al presente que un momento del tiempo adquiere la individualidad imborrable, aquel 'una vez por todas' que luego le permitirán atravesar el tiempo y nos darán la ilusión de la eternidad" (Merleau-Ponty 1993, 432).

Desde esta perspectiva la escritura encarnada en Harwicz se hace temporalidad precisamente a través del presente de la narradora, experiencia abrumadoramente consciente en el que la extensión del acontecimiento memorable en su interioridad procura a su vez el presente para/del lector (Chevallier 2011). A través del anclaje en un verbo que se conjuga mayoritariamente en tiempo presente, la enunciación de la acción produce lo que podríamos llamar una escritura performativa y corpórea: “que percibe los nervios de la materia" (Cixous 1995, 49) y que, mientras nombra, acciona y temporaliza rompiendo también, para el lector, el continuo del tiempo y exigiéndole volver a encontrar su espacio presente (Agamben 2005, 26):

Yo estoy bruta pero llego a notar que mi hijo clama porque regrese, con agua en la boca, viene a rescatarme con sus brazos fornidos, si es que es mi hijo, ahora mismo dudo, cómo pude engendrarlo, lo sigo mirando nadar frenético [...] lo veo venir empujado por el río pero solo cuenta que este averno de deseo dure. Me le voy encima otra vez, y otra, la mandíbula corrida lo beso, qué asco me parece que dice, me tira del pelo, le tiro del pelo, ninguno suelta agarrado de las puntas llegamos hasta arriba y tiramos y tiramos y tiramos tanto que caemos lanzados arena abajo (Harwicz 2015, 74).

Quizá sea su formación como dramaturga lo que dota a su escritura de ese carácter performativo, que además enfatiza el estar haciéndose y en este sentido alude a lo procesual del performance (Taylor 2012, 40-41). En la escritura de Harwicz, el tiempo de la narración es el tiempo así mismo de la acción que va abriendo el lenguaje. El tiempo del acto se vuelve el tiempo del texto, mientras enunciado y enunciación generan un presente de la ficción (Ricoeur 2008, 492):

Soy huérfana, como decir soy mujer casada, como decir, tengo hambre [...] Camino derecho en el predio crecido y dejo atrás la casa deshabitada. Camino buscándola por tierra y por aire, mirando hacia el cielo por si se colgó 
de un paracaídas, del ala de un avión de guerra, desnuda flamea en las ramas. Camino siguiendo el instinto materno que no hay (Harwicz 2014, 75).

\section{LENGUA EROTIZADA Y PALABRA FENOMÉNICA}

El manejo del tiempo narrativo, como presente de la narradora, tiene en las tres novelas esa misma cualidad que performa, en tanto la temporalidad se ancla al presente pero también en cuanto erotiza el lenguaje exponiéndolo en su condición de materia viva.

La voz de la narradora (madre o hija) entrelaza dos experiencias -maternidad y sexualidad-, que al tocarse generan una suerte de fallo. Lo femenino, en particular lo maternal, la imagen de la madre, que a lo largo de la historia cristiana de occidente se articula -volviendo a Kristeva- a través de la imagen de la virgen inmaculada, es un cuerpo privado de sexualidad. Las novelas de Harwicz son, en ese sentido, de una potencia subversiva que desestabiliza esa identidad: en Matate, amor el cuerpo que solicita el hijo es un cuerpo de exuberante sexualidad, que no deja de reorganizar lo real a partir de ese deseo. El maternar parece en esta novela solo un dato adicional, aunque paradójicamente definitivo, frente a un cuerpo que no puede saciarse, como si esa solicitación que desde el niño es de vida o muerte lo hiciera huir en delirio sexual hacia otros cuerpos y que, en la escritura, se transforma en delirio sensual de la palabra.

Una erección, tengo que lograr una erección y me desconecto del lugar, no estoy ahí donde piso, no soy madame la del sombrero ama del adolescente. No avanzo entre yuyos. Una erección para seguir. Los otros en celo no ayudan. Rápido. Cualquier cosa sirve. Una erección para seguir. Una erección como instinto de resistencia, una erección para mantenerme en pie y jugar a las bochas con los otros y hacer de comer. Que algo se alce por encima de las malezas y el musgo seco. Una erección para continuar el camino, el domingo, las compras, los saludos y el supuesto amor a los nietos (Harwicz 2015, 15).

Precoz, tercera novela de la trilogía, en la que se retoma la relación madre-hijo, de hecho se sugiere que es el mismo hijo de Matate, amor pero ahora adolescente ("tal vez mi hijo en unos años", Harcwicz 2012, 81), quien es testigo y cómplice del cuerpo saturado de calentura de la 
madre, una sexualidad que no está direccionada hacia el hijo pero que de manera tangencial no deja de tocarlo. Al fin y al cabo, la madre se sabe en esa relación (volviendo a la figura de la virgen) también esposa e hija (Kristeva 1988, 216):

[...] ahora me besa y nos deshacemos, no madre hijo, dos indocumentados que se cruzan en un paraje, dos aturdidos en la cima de un refugio, dos punks que atraviesan Europa comiendo de la basura pública [...] Tenía que pasar, todo puede pasar entre el amor de la madre y del hijo, por qué no esperar que algún día todo pase y después un recuerdo como no recuerdo en la casa áspera, en la casa miniatura de placard, un falso minuto en la nieve [...] (Harwicz 2015, 56-57).

La identidad maternal descolocada a través de una eroticidad latente, obsesiva, desterritorializada, confronta cada vez la pérdida que acompaña la ruptura entre su cuerpo y el del hijo, en cuya imposible restitución se encuentra también la imposibilidad de ese amor:

[...] ¿qué relación hay entre yo, o incluso más modestamente entre mi cuerpo y ese pliegue-injerto interno que, una vez cortado el cordón umbilical, es otro inaccesible? Mi cuerpo y ....él. Ninguna relación. Nada que ver. $\mathrm{Y}$ esto desde los primeros gestos, gritos, pasos, mucho antes de que su personalidad se haya convertido en mi oponente: el hijo, él o ella, es irremediablemente otro. Que no haya relaciones sexuales es un pobre atestado ante este relámpago que me deslumbra frente al abismo existente entre lo que fue mío y, a partir de ahora solo es irremediablemente ajeno. Intentar pensar en este abismo: alucinante vértigo. Ninguna identidad se tiene en pie. La identidad de una madre solo se mantiene por el cierre bien conocido de la conciencia en la somnolencia de la costumbre, en la que la mujer se protege de la frontera que divide su cuerpo y la destierra de su hijo (Kristeva 1988, 224-25).

Esa misma relación quebrada se expresa de un modo particular en La débil mental, en la que el cuerpo de la hija afectado por su deseo sexual no puede librarse de la presencia de ese otro cuerpo femenino, el de la madre, que parece ser un continuo atentado contra la singularidad del suyo. "La guerra de la hija con su madre" (Kristeva 1988, 229) que atraviesa e interfiere en la sexualidad de esos cuerpos, operando como una sombra que no deja de perturbar su deseo: 
Soy una virgen que vive con su madre en una caravana y en invierno se frotan como dos cetáceos. Soy esa que come hígado de pato con las manos y las uñas rotas. Esa que se ríe y salta en el vendaval de la mano. La concha cerrada hasta la vejez. Y cuando una mañana de nieve encuentra a la madre acostada con la boca abierta y un insecto dentro, se tira encima y la besa. Y se traga el insecto como un hielito (Harwicz 2014, 82).

Lo novedoso de ese desborde sexual que se trunca, que es imposible, vuelve a ser como alcanza la palabra activando su potencial vivo, el carácter erótico de su fisionomía. Esto se materializa, por un lado, como ya lo hemos dicho, en el modo en el que se tensionan y se saturan las relaciones en una combinatoria lingüística que se desborda. $\mathrm{Y}$, por otro lado, en el modo en el que las palabras también performan en su condición fenomenológica -significante cargado de sensualidad- que Marleau-Ponty designó así mismo con una significación existencial: “es necesario que, de una manera u otra, la palabra y el vocablo dejen de ser una manera de designar el objeto para pasar a ser la presencia de este pensamiento en el mundo sensible, y no su vestido, sino su emblema o su cuerpo" $(1993,199)$.

Esto último se juega en estas novelas no solo en el uso bastante libre de la sintaxis, sino de la sensualidad misma del vocablo, del gesto fonético y su sentido emocional que ya modula la experiencia del lector: "el vocablo algo que uno dice, uno oye y ve, el cuerpo acoge los vocablos tal y como los ve" (Merleau-Ponty 1993, 214). El lenguaje dispuesto de este modo extraña al mundo conocido (el de la maternidad) para poder percibir las paradojas que lo constituyen: "la lengua no se apropia de nada, llama, no para hacer venir sino para provocar un alejamiento y que la distancia vibre entre todo" (Novarina 2001, 14). Paradojas que en esta escritura vuelven a manifestarse en el modo a través del cual la impronta de la maternidad, en el lenguaje, produce huecos, vacíos, expresa su esencia que al amar, devora: "Pienso en los sexos de mamá y el señor atornillados volviéndome niña. Pienso en nuestros sexos peludos inventando hijos. Ahí va una madre con las manos detrás de la espalda. Ahí va otra mordiendo el cuello de su cría. Las nubes no me rescatan hoy, no me aspiran" (Harwicz 2014, 52).

Por otro lado, el extrañamiento de la lengua sometida a esos vacíos pone en evidencia la incompletitud de la experiencia y también de la palabra. La experiencia perceptual es siempre parcial y está asociada a la intencionalidad con la que el sujeto elige conectarse con ciertos aspectos de la realidad, señalará Merleau-Ponty. Esto siempre se manifiesta en un tejido 
complejo que orienta el esquema corporal, abriéndolo hacia la experiencia parcial de cualquier fenómeno (Merleau-Ponty 1993, 231). Un lenguaje fragmentado, un ritmo quebrado, da cuenta no solo de la cualidad subjetivizada de la experiencia sino de la falta que la constituye, la manifestación de lo que no se puede asir de cada momento. Es, paradójicamente, desde esa incapacidad que a la vez surge la necesidad de nombrar: "la intención de hablar solo puede hallarse en una experiencia abierta, aparece como la ebullición en un líquido, cuando en el espesor de un ser se constituyen unas zonas de vacío que se desplazan hacia el exterior" (Merleau-Ponty 1993, 211). Acontecimiento del habla que sucede no necesariamente desde su funcionalidad para expresar un pensamiento, sino para estructurar una experiencia que urge exteriorizarse. Es esta urgencia precisamente lo que se percibe a lo largo de los monólogos en estas novelas, leemos en Matate, amor:

Quiero ir al baño desde que terminó el almuerzo pero es imposible hacer otra cosa que ser madre. Y dale con el llanto, llora, llora, llora, me va a trastornar. Soy madre, listo. Me arrepiento, pero ni siquiera lo puedo decir. A quién. ¿A él sentado en mis rodillas, metiendo la mano en mi plato de restos fríos, jugando con un hueso de pollo? ¡No! Dejá eso que te atragantás. Le tiro una galletita. Me la devuelve. Tengo la boca llena de su saliva, de migas. Tengo tomate pegado en mi brazo. No lo dejo terminar y le meto otra galleta, se atora. No me hago cargo de lo que pueda pensar de mí. Lo traje al mundo, ya es suficiente [...] (Harwicz 2012, 99).

El lenguaje opera, a lo largo de toda la trilogía, precisamente como estructurador de la experiencia, traspasado por el ejercicio fallido de todo amor maternal. En la fisionomía de la escritura asoma para el lector la reconstrucción de una experiencia que desde sus paradojas da cuenta de la violencia y la pasión de ese afecto. Es una escritura que atraviesa, en este sentido, el cuerpo del lector, arrojándolo al lenguaje en su plena condición material, en su existencia corporal, llevándolo también a sus límites en una experiencia que lo solicita y lo confronta con lo más abyecto, con lo impensado y lo imposible de la imagen, ahí la potencia y la radicalidad de esta escritura:

La casa está llena de ronquidos y solo somos dos. Soy un espectro, camino con la panza apretujada, con el demonio en la panza, cae a mis pies, me muevo entre habitaciones. No hay nada, tampoco diría dolor, no es ni eso, 
son más bien azulejos fríos, si no sirve meter la cabeza en el tigre, para qué días. Busco por la casa algo y no sé qué. Deambulo, veo a mamá sin contornos lavarse, rayarse. Tarde para haber vivido, temprano para eliminarse. Me meto en su cama, no la despierto, me subo a ella y la abrazo, estoy perdiendo consistencia y solo soy una especie de idea [...] Me están amamantando. Me divorcio cerebralmente de todo y ya no estoy en esta casona entre las patas de mamá ni con la boca sorbiendo su pezón [...] (Harwicz 2014, 21- 22). *

\section{Bibliografía}

Agaud, Ana. 2015. “El ritmo y la libertad: semántica estética, terapia equívoca, paradojas”. En Teresa Aizpún, Eva Fernández del Campo y Cayetana Ibáñez, editores. Ritmo. El pulso del arte y de la vida. Madrid: Abada Editores.

Agamben, Giorgio. 2005 [1970]. El hombre sin contenido. Barcelona: ALTERA.

—. 2016. “¿Qué es la creación?”. En El fuego y el relato. México: Sexto Piso.

- 2017. El uso de los cuerpos. Buenos Aires: Adriana Hidalgo.

Chevallier, Jean Frederic. 2011. “Fenomenología del presentar”. En Literatura: teoría, historia, critica. Vol. 13, n. ${ }^{\circ}$ 1. Universidad Nacional de Colombia.

Cixous, Hélène. 1995 [1992]. La risa de la medusa. Barcelona: Anthropos.

Harwicz, Ariana. 2012. Matate, amor. Madrid: Lengua de Trapo.

—. 2014. La débil mental. Buenos Aires: Mardulce.

- 2015. Precoz. Buenos Aires: Mardulce.

Kristeva, Julia. 2013 [1980]. Poderes de la perversión. México: Siglo XXI.

—. 1988 [1983]. "Stabat Mater". En Historias de amor. México: Siglo XXI.

López, Irene. 2015. "El arte encarna la vida: ritmo, movimiento y cuerpo en la modernidad europea”. En Teresa Aizpún, Eva Fernández del Campo y Cayetana Ibáñez, editores. Ritmo. El pulso del arte y de la vida. Madrid: Abada Editores.

Merleau-Ponty, Maurice. 1993 [1945]. Fenomenología de la percepción. México: Planeta-Agostini.

Novarina, Valere. 2001. Ante la palabra. Valencia: Pre-textos.

Ricoeur, Paul. 2008 [1995]. Tiempo y narración II. México: Siglo XXI.

Taylor, Diana. 2012. Performance. Buenos Aires: Asunto Impreso Ediciones. 